mococcus and its pathogenicity is very similar in man and animals. At present, the streptococcal disease, Streptococcus suis (group R) is considered to be related to management conditions, herd selection and stimulated by stress situations such as vaccinations, transports, etc.

\title{
Water intake of pregnant sows in intensive rearing conditions. Relationships with some urine characteristics
}

\author{
F. MADEC \\ Ministère de l'Agriculture, Station de Pathologie Porcine, B.P. 9, \\ 22440 Ploufragan
}

A study was carried out in 8 breeding herds in Brittany (France). This study was focused on the daily water intake of pregnant sows and its distribution along the 24-h period. The sows were tethered. Diet and water were provided individually in a trough. Mean water consumption was 17 liters $/ 24 \mathrm{~h}$. From one day to another, individual water intake showed moderate fluctuations, but large between-sow differences were observed. Under our conditions, about 75 p. 100 water was consumed during feeding in spite of the permanent water availability in the trough. The difficulties of adaptation to a new environment, leg injuries, sow condition and stage of pregnancy influenced the level of water intake. The probability of finding abnormalities in the urine (nitrite, bacteria, cristals) increased with decreasing water consumption. A water amount of 15 liters $/ \mathrm{d} /$ pregnant sow was advised. As it was difficult to directly control the water intake, a low consumption could be detected by recording the Urine Specific Gravity (U.S.G.). The U.S.G. value of the first morning urine exceeding 1012, indicated a low water intake.

\section{Moving activity of pregnant tethered sows : determination of some factors of variations}

\author{
R. CARIOLET *, R. DANTZER ** \\ *Ministère de l'Agriculture, Station de Pathologie Porcine, B.P. 9, \\ 22440 Ploufragan \\ ** Groupe I.N.R.A. Stress et Physiopathologie de l'Adaptation, I.N.S.E.R.M. U 259, \\ Domaine de Carreire, rue Camille Saint-Saëns, 33077 Bordeaux Cedex
}

Moving activity of 150 Large White and Large White $\times$ Landrace pregnant sows, tethered by a thoracic belt or by the neck, was studied in 7 herds by means of a technique using photoelectric cells. This technique allows to distinguish between the standing or the laying position. The standing position was observed for 245 minutes per day, on an average. About 10 getting-ups were recorded per day. The standing position was mainly noticed during the day in connection with feeding. Variations between individuals in the time spent standing were much larger within the same than between the different herds.

The main factors of variations were litter order (primiparous or secondparous sows being less active than multiparous ones), fleshiness (a deterioration was accompanied by a relative hyperactivity), limb quality (sows having a bad stance spent less time standing) and gestation stage (the activiy was smaller in early and late gestation). The relationships between these different factors were shown using the correspondance analysis. Results obtained underlined the importance of an objective characterization of the sow response to its environment. 